\title{
Comparison of transdermal nitroglycerin and intracavernous injection of papaverine in the treatment of erectile dysfunction in patients with spinal cord lesions
}

\author{
R Renganathan, B Suranjan and T Kurien \\ Department of Physical Medicine and Rehabilitation, Christian Medical College and Hospital, Vellore and Clinical \\ Epidemiology Unit, Christian Medical College and Hospital, Vellore, India
}

\begin{abstract}
This study was done to evaluate the effectiveness of transdermal nitroglycerin in the treatment of erectile dysfunction in males with spinal cord lesions as compared to the treatment with intracavernous injection of papaverine. The study design used was an open, randomized, cross over trial of intracavernous injection papaverine versus transdermal nitroglycerin. Twenty eight male patients with spinal cord lesions with erectile dysfunction were included in the study, and were subjected to intracavernous injection of papaverine and transdermal nitroglycerin with an interval of 2 weeks as the wash out period. Objectively, the times taken for the onset and the duration of erection were noted. The length of the penis and its circumference at its base were measured at intervals until the erection subsided. The volume of the penis at the onset and at the peak of erection was calculated. Twenty six patients (ie $93 \%$ ) who received an injection of papaverine, and 17 (ie 61\%) of the patients who received nitroglycerin showed a complete response. The difference was statistically significant $(P=0.004)$. Nine $(32 \%)$ patients had complications with the injection of papaverine. The only complication noted with the application of a nitroglycerin patch was mild headache, experienced by six $(21 \%)$ patients. It was concluded from the study that intracavernous injection of papaverine is more effective than transdermal nitroglycerin in the treatment of erectile dysfunction in patients with spinal cord lesions.
\end{abstract}

Keywords: spinal cord lesion; erectile dysfunction; intracavernous papaverine; transdermal nitroglycerin

\section{Introduction}

Sexual rehabilitation is often overlooked or is not sufficiently considered in male spinal paralysed people. Erectile dysfunction is the inability of the man to attain erections sufficiently rigid for vaginal penetration and sexual satisfaction. ${ }^{1}$ This study was done to evaluate the effectiveness of transdermal nitroglycerin in the treatment of erectile dysfunction in males with spinal cord lesions as compared with intracavernous injection of papaverine.

The other objectives of the study were to study the complications and the patient's acceptance noted with intracavernous injection of papaverine and with transdermal nitroglycerin. At present, the intracavernous injection of papaverine is an established treatment method used in the management of erectile dysfunction in spinal cord-injured. Transdermal nitroglycerin is being compared with the 'gold standard' in this study. The hypothesis is that transdermal nitroglycerin will be safer and more effective than the intracavernous injection papaverine in these patients.

Correspondence: R Renganathan
The topical agents that have been studied in the management of erectile dysfunction are topical minoxidil, ${ }^{2,3}$ prostaglandin-E1 $0.04 \%$ gel, ${ }^{4}$ papaverine topical gel $^{5}$ and nitroglycerin $2 \%$ ointment. $^{6-9}$ Intraurethral prostaglandin E-2 cream has been reported to have beneficial effects on erectile dysfunction. ${ }^{10}$ Organic nitrates and nitrites are well recognised as vasodilators through the relaxant effects on vascular smooth muscle. Among the best known of these compounds is nitroglycerin, which is readily absorbed after topical application. ${ }^{11}$

Nitroglycerin paste has been reported to have beneficial effects on erectile dysfunction in a few studies. ${ }^{12}$ Headache (in patients and partners) is a common side effect. It is well known that ointments cannot implement the principle of rate control. Therefore, will the use of transdermal patches have similar effects?

Why should we use a transdermal route of administration? Rate controlled, transdermal drug delivery has some advantages which include the convenience of application (and removal), the ability to deliver the drug directly to the general circulation 
and therefore to bypass the portal system and the liver. The delivery system is designed so that the system, not the skin, controls the rate of drug entry into the circulation. ${ }^{13,14}$

Transderm-NitroSystem consists of a nitroglycerinreleasing medicated pocket whose surface is coated with a layer of silicone adhesive. In this system the drug reservoir, silicone fluid, is enclosed within a impermeable shallow compartment that is covered with a constant surface area of microporous ethylenevinyl acetate copolymer membrane. This membrane controls the rate of nitroglycerin release when the patch makes contact with the skin surface. The diagrammatic representation of the membrane permeation-controlled drug delivery system is given in Figure $1.15-17$

\section{Materials and methods}

Study design

The study design used was an open randomized cross over trial of intracavernous injection papaverine versus transdermal nitroglycerin in the management of erectile dysfunction in spinal cord lesions.

\section{Sample size}

The study was planned to detect a difference of more than $20 \%$ between the two groups in the number of patients who had a complete response. Keeping the Type I and Type II errors at 5\% and 10\% respectively the sample size needed was 25 . The difference ie $<20 \%$ is permitted because of the added advantage of transdermal nitroglycerin being a non-invasive technique.

\section{Inclusion criteria}

Twenty eight male patients with spinal cord lesions with erectile dysfunction, admitted to the Rehabilitation Institute, C.M.C.H. were included in the study. They underwent comprehensive rehabilitation which

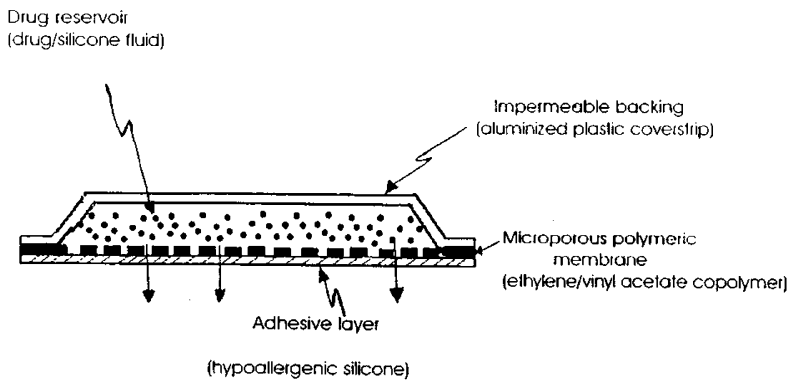

Membrane permeation-controlled drug delivery system. included gait training, training in activities of daily living and a bladder and bowel rehabilitation program.

\section{Exclusion criteria}

(i) Duration of lesion $<3$ months; (ii) Age $<16$ years and $>60$ years; (iii) Patients with complications such as active infection, hypospadias, etc; (iv) Patients with a history of impotence prior to injury.

\section{Ethics}

Informed consent was obtained from all the patients before the start of the study.

\section{Randomization}

A simple randomization technique was used to allocate patients to the two treatments in the first period.

\section{Intervention}

The patients enrolled in the study were subjected to pharmacological intervention, ie intracavernous injection of papaverine and transdermal nitroglycerin with an interval of 2 weeks as wash out period. Two sessions of sexual counselling were given to the patients before the start of the study. Reassurance, relevant information on the basic concepts of bladder management prior to sexual stimulation and the prevention of autonomic dysreflexia during intercourse were given to each patient.

The study was done in a separate room giving the respect to the privacy of the patient.

To start with, a rubber band was applied firmly to the base of the penis following which $10 \mathrm{mg}$ of an undiluted injection of papaverine hydrochloride (manufactured in the Christian Medical College and Hospital, Vellore, India $-40 \mathrm{mg} / \mathrm{ml} ; 10 \mathrm{ml}$ vials) was injected along the lateral aspect of the penile shaft into the corpora cavernosa using $2.5 \mathrm{cc}$ disposable syringes and 26 gauge needles by the principal investigator. Digital pressure with one finger was applied on the injection site for about $2 \mathrm{~min}$. The rubber band was removed after $5 \mathrm{~min}$. If the patient did not have a complete response

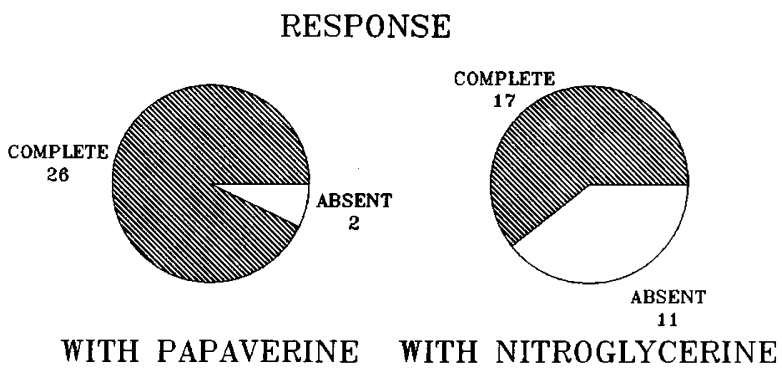

Figure 2 
after $15 \mathrm{~min}$, a dose of $20 \mathrm{mg}$ was tried the following day. If the patient did not experience a complete response also to this dose, a dose of $40 \mathrm{mg}$ was tried and likewise up to a maximum of $60 \mathrm{mg}$. Alternate sides for the injections were used with consecutive doses.

With nitroglycerin, the nitroglycerin patch (Transiderm-Nitro-CIBA Geigy) of $5 \mathrm{mg} / 24 \mathrm{~h}$ was applied to the ventral surface of shaft of the penis after the application of a firm rubber band to the base of penis. The patch and the rubber band were kept on for $1 \mathrm{~h}$ after the application.

In both of the treatment studies, the following outcomes were noted. Objectively, the time taken for onset of erection and the duration of erection were noted. The length of the penis and its circumference at its base were measured using an inch tape at the beginning and at 5, 15, 30, $60 \mathrm{~min}$ and every $1 \mathrm{~h}$ thereafter until the erection subsided. The circumference was divided by two pi to give the radius. The volume of the penis at the beginning and at the end of the procedure was calculated using the formulaVolume of the penis $(\mathrm{cu} . \mathrm{cm})=22 / 7 \times$ square of the radius of the penis $(\mathrm{cm}) \times$ length of the penis $(\mathrm{cm})$. The change in volume of the penis $(\mathrm{cu} . \mathrm{cm})$ is the difference between the initial and final volumes. An Erectile Index was calculated by multiplying the change in volume of the penis (cu. $\mathrm{cm}$ ) and duration of erection (h).

Subjectively the response to the largest dose administered to each patient was classified as complete, partial or absent. A complete response was an erection with full rigidity. A partial response was an erection with some rigidity. If there is no noticeable reaction, it was taken as an absent response. The patients' acceptance of the two drugs was noted on a progressive scale of 1 to 10 .

Complications and their severity were recorded. The blood pressure was measured when the nitroglycerin patch was used at the time of application and immediately after removal of the patch.

The value of the erectile index was compared in the two treatment groups using the paired $t$ test.

The proportion of patients who had a complete response and a partial response in the two treatment periods was compared using Macnamer's Chi Square test. The patients' acceptance between the two groups, and the incidence of complications was compared using the Chi Square test.

\section{Results}

The erectile index in the two groups was compared. The difference between the two treatments was statistically significant $(P=0.045)$ in favour of the injection papaverine. The mean value for the erectile index in the papaverine group was 164.5 and in the nitroglycerin group was 106 .

Twenty six patients (ie 93\%) who received injection papaverine and 17 (ie $61 \%$ ) of the patients who received nitroglycerin showed a com- plete response. The difference was statistically significant $(P=0.004)$. This is represented in the pie diagram in Figure 2.

There was no significant difference in the patients' acceptance of the two treatments. The mean for the patients' acceptance level was 6 (on a scale of 1 to 10) for nitroglycerin patch and 6.4 for injection papaverine. No significant difference was found between spastic and flaccid patients who showed a complete response. Of the 28 patients, 18 were spastic and 10 were flaccid.

Seventeen of the 18 spastic patients had a complete response with an injection papaverine, and one patient had an absent response. Nine of the 10 flaccid patients had a complete response with the injection papaverine and one had an absent response.

Twelve of the 18 spastic patients had a complete response with the nitroglycerin patch and six patients had an absent response. Five of the 10 flaccid patients had a complete response with the nitroglycerin patch and five had an absent response.

Nine $(32 \%)$ patients had complications with the injection of papaverine; eight had mild oedema which developed after the second injection. The oedema did not require any intervention and subsided spontaneously in 3-4 days. One patient experienced a prolonged erection which lasted for $6 \mathrm{~h}$ and subsided after the application of $2 \%$ lignocaine jelly locally over the penile shaft. The only complication noted with the application of a nitroglycerin patch was mild headache, experienced by $6(21 \%)$ patients. No treatment was necessary. The difference was not statistically significant $(P$ value 0.36$)$.

The time taken for the occurrence of the maximum length and the change in length with each drug were also studied. The onset of erection started about 15 min after the application of the nitroglycerin patch and lasted for about an hour, following which it started to subside. Regarding the injection of papaverine, erection started in $5 \mathrm{~min}$ and subsided within $30-45 \mathrm{~min}$ in most of the patients. This was only seen with the injection of $10 \mathrm{mg}$ of papaverine. Increasing doses (ie $20 \mathrm{mg}, 40 \mathrm{mg}, 60 \mathrm{mg}$ ) showed that the peak of erection was maintained for a longer duration and it took about $2-3 \mathrm{~h}$ for the erection to subside.

\section{Discussion}

This study compared the effectiveness of transdermal nitroglycerin and intracavernous injection of papaverine for erectile dysfunction in patients with spinal cord lesions. Our most important finding is that the intracavernous injection of papaverine is more effective than is the use of transdermal nitroglycerin for the treatment of erectile dysfunction in those with spinal cord lesions. The erectile index and the nature of responses were better, in favour of the injection of papaverine when compared with transdermal nitroglycerin. Moreover the patients' acceptance was margin- 
ally in favour of the injection of papaverine, though it was not statistically significant.

In studying the number of spastic/flaccid patients who showed a complete response with the injection of papaverine and with transdermal nitroglycerin, it was found that one spastic patient and one flaccid patient did not shown any response with papaverine. This flaccid patient who did not respond had a vascular etiology for his paraparesis.

In the case of the spastic patient who did not respond, he refused to try increasing doses of the papaverine after a dose of $20 \mathrm{mg}$ since he developed oedema. Regarding nitroglycerin, five flaccid patients and six spastic patients did not respond. Though the results were not statistically significant, these results raise an issue which has not been dealt with in previous similar studies.

All six patients who had complications with transdermal nitroglycerin had a mild headache, which started half an hour after the application of the patch, lasted for about half an hour after its removal and was relieved spontaneously. No patient had a fall in blood pressure. Eight of the nine patients who had complications with papaverine, had mild oedema which developed after the second injection and subsided in 3-4 days. In patients who developed oedema further doses of injection were withheld until the oedema subsided completely. It has been reported that patients with neuropathic impotence are more likely to have sustained erections. However, in our study only one patient experienced a prolonged erection which lasted for $6 \mathrm{~h}$ and subsided with the local application of $2 \%$ lignocaine jelly over the shaft of the penis.

The results of the study also show that there is no relation between age, type of lesion (spastic of flaccid) or duration of lesion and the response noted with either drug.

The erectile index which was proposed in this study as a product of change in volume of the penis and duration of erection may not be the best method to assess the erectile response to any drug because the duration of erection may significantly alter the results causing a bias.

There are certain issues which have to be highlighted from this study.

In classifying the subjective response to each drug, a complete response meant erection with full rigidity and a partial response meant erection with some rigidity.

Now, the concept of full rigidity has not been clearly defined in the literature and is therefore subject to variation from patient to patient. More evidence is required.

Considering the matter of cost, $5 \mathrm{mg}$ nitroglycerin patch costs Rs.50.00, and $10 \mathrm{mg}$ nitroglycerin patch costs Rs.68.00. One vial $(10 \mathrm{ml})$ of papaverine for injection (each $\mathrm{ml}$ contains $40 \mathrm{mg}$ of the drug) costs Rs.13.00; disposable syringe with a needle costs Rs.5.00 and 26 gauge disposable needle costs Rs.2.00. Therefore it is clear that the administration of intracavernosal injection papaverine is cheaper than is the application of nitroglycerin patch. This may be one of the reasons why certain patients prefer the papaverine injection to the nitroglycerin patch.

The duration for the rubber band and the patch being left on the penis may have played a role in influencing the results of our study, since the duration of $1 \mathrm{~h}$ followed by us was purely arbitrary. Other studies have not specified the duration of the application of a rubber band on the penis. Regarding the use of the nitroglycerin patch, the patch and the rubber band were kept on the penis for $1 \mathrm{~h}$, and the erection began to subside once they were removed. This may be the ideal duration for the rubber band being left on the penis. Whereas in the case of the intracavernous injection of papaverine, the rubber band was removed after $5 \mathrm{~min}$, irrespective of the response. With intracavernous injection of $10 \mathrm{mg}$ papaverine, if there is no response within $5 \mathrm{~min}$, it may be better to leave the rubber band on the penis for 10 to $15 \mathrm{~min}$ rather than to try a higher dose of the drug the next day.

Though we could increase the dose of the injection of papaverine, we could not do the same with the nitroglycerin. Higher doses of nitroglycerin in the patch could not be tried as headache was a complication in six of our patients. No specific predisposing factor could be found for the development of headache in these six patients.

The turgidity of the penis may be a more reliable indicator of the erectile response of a drug rather than the volume of the penis or its length. Therefore validated instruments to measure the turgidity of the penis may be used in further studies.

Our study also did not evaluate the partner's satisfaction after intercourse following the use of either drug. This important aspect should not be overlooked in further similar studies.

This study showed only the short-term complications of each drug. However, the long-term complications are still unknown. Since quite a number of patients using transdermal nitroglycerin obtained a complete response, should this be tried prior to the injection of papaverine? The answer will only be known if the long term effects of the injection of papaverine and its safety are known.

\section{Conclusion}

In conclusion, we have found that the intracavernous injection of papaverine is more effective than is transdermal nitroglycerin in the treatment of erectile dysfunction in patients with spinal cord lesions.

\section{References}

1 Seth EL, Arnold M, George JC. A review of erectile dysfunction: new insights and more questions The Journal of Urology 1993 May; 149: $1246-1255$. 
2 Radomski SB, Herschorn S, Rangaswamy S. Topical Minoxidil in the treatment of male erectile dysfunction. The Journal of Urology 1994 May; 151: 1225 - 1226.

3 Giorgio C. Minoxidil versus nitroglycerin: A prospective doubleblind controlled trial in transcutaneous erection facilitation for organic impotence. The Journal of Urology 1991 July; 146: 50 53.

4 Edward DK, Kevin TM. Topical prostaglandin E1 for treatment of erectile dysfunction. The Journal of Urology 1995 June; 153: $1828-1830$

5 Edward DK, Ragab E, Kevin TM. Papaverine topical gel for treatment of erectile dysfunction. The Journal of Urology 1995 Feb; 153: $361-365$

6 Sonksen J, Biering-Sorensen F. Transcutaneous nitroglycerin in the treatment of erectile dysfunction in spinal cord injured. Paraplegia 1992 Aug; 30(8): 554-557.

7 Boris DN, Douglas CA. Nitroglycerin ointment in the treatment of impotence. The Journal of Urology 1993 Oct; 150: 1241 - 1243.

8 John WM. Impotence responsive to glyceryl trinitrate. Am J Psychiatry 1977 Aug; 922-925.

9 Heaton JPW et al. Topical glyceryl causes measurable penile arterial dilation in impotent men. The Journal of Urology 1990 April; 143: 729 - 731 .

10 Wolfson B, Pickett S, Scott NE, Dekernion JB, Rajfer J. Intraurethral prostaglandin E-2 cream: a possible alternative treatment for erectile dysfunction. The Journal of Urology 1993; 42: $73-75$.
11 James AO et al. Topical nitroglycerin. A potential treatment for impotence. The Journal of Urology 1989 Mar; 141: 546-548.

12 Meyhoff HH, Rosenkilde P, Bodker A. Non-invasive management of impotence with transcutaneous nitroglycerin. British Journal of Urology 1992; 69: 88-90.

13 Ferid M. Drugs used for the treatment of angina: organic nitrates, calcium-channel blockers and beta-adrenergic agonists. In: Alfred GG, Theodore WR, Alan SN, Palmer T. The Pharmacological Basis of Therapeutics, Perganon Press 1991. $764-783$.

14 Peter G. Rate controlled drug delivery. The New England Journal of Medicine 1982 Jul; 307(5): 286-290.

15 Douwe DB. Rationale for rate controlled drug delivery of cardiovascular drugs by the transdermal route. American Heart Journal 1984 Jul; 108(1): $195-200$.

16 Yie WC. Piscataway NJ. Pharmaceutical consideration of transdermal nitroglycerin delivery: the various approaches. American Heart Journal 1984 Jul; 108(1): 207 - 216.

17 Jane ES, Palo AC. Pharmacokinetics of nitroglycerin and clonidine devliered by the transdermal route. American Heart Journal 1984 Jul; 108(1): $217-222$. 